Letter to Editor

\section{Criteria for paediatric oral liquid form}

\section{Daniela Gavrus ${ }^{1}$, Ferran Bossacoma Busquets ${ }^{1,2 *}$, Josep Maria Català ${ }^{1}$, Joan Lluis Vinent Genestar ${ }^{1}$ and Miquel Villaronga Flaque $^{1}$}

1Servei de Farmàcia Hospital Sant Joan de Déu, Spain

${ }^{2}$ Servei de Farmàcia Fundació Salut Empordà, Spain

Paediatric hospitals frequently have to face the lack of commercially available medicines suitable or even licensed for their use in paediatrics. Thus, only one-third of all medicines approved by the European Medicines Agency over the period of 1995 to 2005 were licensed for use in children [1]. Furthermore, authorized paediatric medicines, especially in younger children and neonates, may not always be age appropriate regarding the dose, suitability of dosage forms, and excipients contents. In order to solve this deficiency, the European Medicines Agency (EMA) published in December 2016 the regulation of medicinal products for paediatric use and amending Regulation [2] and in December 2007, the World Health Organization started the initiative "Make medicines child size" to improve the availability and access to child-specific medicines [3]. The paediatric regulation has had a very positive impact on paediatric drug development [4], even those positive results, not even spread among all therapeutic areas, but concentrate in some, often linked to research priorities in adults rather than children.

As in adults, the oral route is the preferred route of administration in children. Paediatric medicines should be appropriately designed for the target age group, oral liquid formulations, such as solutions, drops and suspensions, are commonly the best options for young children, because they allow weight based dosage and are easy to swallow. Also, oral liquid medicines are likely to be administered by feeding tube to patients who are tube fed due to their condition or age related limitations as, for example, pre-term neonates, unable to swallow but able to receive enteral feeds.

The limitations of the oral liquid medicines are their usually short chemical, physical, or microbiological stability. Their higher complexity can involve a broader range of excipients, frequently used as preservatives, sweeteners, fillers, solvents, and colouring agents. The selection of excipients for paediatric medicines is challenging because not even the inactive ingredients guide list of the "US Food and Drug Administration (FDA)" has been validated for paediatric use [5].

\author{
More Information \\ *Address for Correspondence: \\ Ferran Bossacoma Busquets, Servei de \\ Farmàcia Hospital Sant Joan de Déu, Spain, \\ Tel: 0034932532133 ; \\ Email: fbossacoma@hsjdbcn.org; \\ fbossacoma@fsjd.org \\ Submitted: March 18, 2021 \\ Approved: March 25, 2021 \\ Published: March 26, 2021 \\ How to cite this article: Gavrus D, Busquets FB, \\ Català JM, Genestar JLV, Flaque MV. Criteria for \\ paediatric oral liquid form. Arch Pharm Pharma \\ Sci. 2021; 5: 018-019. \\ DOI: 10.29328/journal.apps.1001026 \\ ORCiD: orcid.org/0000-0002-4350-2428 \\ Copyright: (c) 2021 Gavrus D, et al. This is \\ an open access article distributed under the \\ Creative Commons Attribution License, which \\ permits unrestricted use, distribution, and \\ reproduction in any medium, provided the \\ original work is properly cited. \\ Check for updates \\ OPEN ACCESS
}

To analyse the importance of the lack of paediatric available commercialized medicines in a 314 beds Spanish mother and child hospital, three studies were conducted:

One study of readiness of children-friendly oral medicines was conducted, for the totality of the 148 liquid oral medicines of the hospital's formulary; a 35\% of the different active substances are needed to be prepared as compounded oral form. A $90 \%$ of those, due to the lack of suitable medicines commercially available (dosage forms, administration volume, dosage form size); $4 \%$ were available in international market but with an inappropriate excipient for children; $6 \%$ available active substance and correct form with different indication.

The second one, a cross sectional study, was make from February to April 2018, the percentage of compounded medicines prescribed was checked in regard to all oral medication prescribed, and as a result evidenced that the shortage mainly affects relevant services such as cardiac surgery $47 \%$, cardiology $30 \%$, haematology $21.1 \%$ and oncology with $20 \%$.

A third study, in the light of the publication of the European guideline of "Excipients in the labelling and package leaflet of medicinal products for human use" an analysis of the 96 commercial oral liquid forms included on the centre formulary was carried out. 
As results was detected that $47 \%$ of those contained benzyl alcohol, ethanol or propylene glycol and esters of propylene glycol, excipients contraindicated in neonates and children less than 6 years. A 32\% contains at least one excipient contraindicated in patients with metabolic disorders (aspartame, fructose, sorbitol or phenylalanine) [6] and a $87 \%$ contained as least one potential harmful excipient(Aspartame, azo colouring agents, benzoic acid (E 210) and benzoates, benzyl alcohol, cyclodextrins, ethanol, fructose, glucose, glycerol (E 422), gluten, sulphites including metabisulphites, sucrose, soya oil/hydrogenated soya oil, sorbitol (E 420), propylene glycol (E 1520) and esters of propylene glycol, phenylalanine, parahydroxybenzoates and their esters, mannitol (E 421), maltitol (E 965), macrogolglycerol ricinoleate) [7].

After those results, specific criteria are usually needed to be implemented in the procurement of oral liquid formulations taking into account the fallowing requirements:

Excipients not suitable for the paediatric population should be listed in the package leaflet and avoid those contraindicated in neonates and children less than six years. Maximum dosage or concentration should be presented in the summary product characteristics since daily and cumulative intakes of excipients may also be a problem, thus, to prevent an accumulation of these in the long term, low concentration of potentially harmful excipients will be selection criteria.

Regarding the formulation, solutions are the first option as they allow dosage uniformity and suspensions presents disadvantages as the risks of under- and overdosing to the child as a result of inadequate shaking and the reconstitution out of the pharmacy adds a new error point. Unless otherwise justified, oral drops allow dosing in small volumes and will only be considered acceptable for paediatric medicines containing active substances with a wide therapeutic window [8].

To avoid medication errors, American Society of HealthSystem Pharmacists (ASHP) and FDA recommend the standard, when they are available and are therapeutically appropriate [9] and the volume of the dose of an oral liquid preparation may have an impact on the patient acceptability.

To improve the adherence to paediatrics, tastiness attributes of an oral form is relevant because children have a low tolerance for disagreeable savour. Patient's preferences may differ between children and adults, as children prefer sweet and salty flavours, and dislike bitter and peppermint flavour [10]. A paediatric preparation with a neutral or with a specific and generally acceptable taste is the main solution.

For the packaging: solutions solvents, other than water should be provided as part of the medicinal product. Oral liquid paediatric dosage forms should be packaged together with an appropriate measuring device, unless those are widely available. The device should be suitable to measure all recommended doses [8]. Due to its use in paediatrics and its possible good flavour, they must have safety plugs to avoid over dosage.

Preservation requests are also relevant, as medicines that do not need to be stored in the refrigerator will be of first choice due to the transport and storage facilities.

As a summary, despite the scientific advances made in research and development of new treatments for adults, the options for children lag behind significantly. Common formulations commercialized must be available as liquid oral presentations and even they are approved for children appropriate excipients must be considerate during the drug development.

\section{References}

1. Ceci $A$, Felisi M, Baiardi $P$, Bonifazi $F$, Catapano $M$, et al. Medicines for children licensed by the European Medicines Agency (EMEA): the balance after 10 years. Eur J Clin Pharmacol. 2006; 62: 947-952. PubMed: https://pubmed.ncbi.nlm.nih.gov/17021892/

2. Regulation (EC) No 1901/2006 of the European Parliament and of the Councilof 12 Decembre 2006 on medicinal products for Paediatric use, OJ L 2006; 378:1. https://ec.europa.eu/health/sites/health/files/ files/eudralex/vol-1/reg_2006_1901/reg_2006_1901_en.pdf

3. World Health Organization. Annex 5. Development of paediatric medicines: points to consider in formulation. World Health Organ Tech Rep Ser. 2012; 970: 197-225. http://apps.who.int/medicinedocs/ documents/s19833en/s19833en.pdf

4. European Medicines Agency . 10-year report to the European commission - General report on the experience acquired as a result of the application of the Paediatric Regulation. 2016. EMA/231225/2015. https://ec.europa.eu/health/sites/health/files/files/paediatrics/2016_ pc_report_2017/ema_10_year_report_for_consultation.pdf

5. Fabiano V, Mameli C, Zuccotti GV. Paediatric pharmacology: remember the excipients. Pharmacol Res. 2011; 63: 362-365. PubMed: https://pubmed.ncbi.nlm.nih.gov/21241804/

6. Breikreutz J, Boos J. Paediatric and geriatric drug delivery. Expert Opin Drug Deliv. 2007; 4: 37-45.

PubMed: https://pubmed.ncbi.nlm.nih.gov/17184161/

7. European Commission. Annex to the European Commission guideline on 'Excipients in the labelling and package leaflet of medicinal products for human use' (SANTE-2017-11668). 2017. https://www. ema.europa.eu/documents/scientific-guideline/annex-europeancommission-guideline-excipients-labelling-package-leaflet-medicinalproducts-human_en.pdf

8. European Medicines Agency. Guideline on pharmaceutical development of medicines for paediatric use. EMA Rev. 2012. https:// www.ema.europa.eu/documents/scientific-guideline/draft-guidelinepharmaceutical-development-medicines-paediatric-use_en.pdf

9. Billstein-Leber M, D Carrillo CJ, Cassano AT, Moline K, Robertson JJ. ASHP Guidelines on Preventing Medication Errors in Hospitals. Am J Health-Syst Pharm. 2018; 75: 1493-517.

PubMed: https://pubmed.ncbi.nlm.nih.gov/30257844/

10. Ivanovska V, Rademaker CMA, van Dijk L, Mantel-Teeuwisse AK. Pediatric Drug Formulations: A Review of Challenges and Progress. Paediatrics. 2014; 134: 361-372.

PubMed: https://pubmed.ncbi.nlm.nih.gov/25022739/ 